\title{
El apoyo democrático en las zonas rurales de los países andinos centrales (2006-2016)
}

\section{Diego Acedo-Díaz}

Recibido: 08-jul-20

Aprobado: 04-nov-20

doi: $10.46476 /$ ra.v1i2.48

\section{Resumen}

En lo referente a la democracia en las zonas urbanas y rurales, las ciencias sociales han tendido a ligar la democracia con el desarrollo de la urbanización. Desde distintos enfoques (institucionalista, culturalista o el historiográfico) se ha establecido una línea común entre urbanización y apoyo a la democracia. Sin embargo, en este escrito, a partir del análisis en los países andinos centrales, se ha podido observar que en Ecuador y Bolivia las zonas rurales han mostrado un mayor apoyo al sistema democrático frente a Perú durante una década (2006-2016). El propósito de este trabajo se enfoca en resolver el porqué de esta tendencia a través de la técnica de sistemas similares; de esta forma, se halló que el fenómeno de los conflictos armados sucedidos desde la segunda mitad del siglo XX se sitúa como una posible condición explicativa.

Palabras clave: democracia, rural, terrorismo, Bolivia, Ecuador, Perú. 


\section{Abstract}

When it comes to democracy in urban and rural areas, the social sciences have typically tied democracy to urban development. A common thread between urban development and support for democracy has been established based on a range of approaches (institutionalist, culturalist, or historiographic). However, through an analysis of the countries of the central Andes, this paper finds that, in Ecuador and Bolivia, rural areas have shown the greatest support for the democratic system compared to Peru over a decade-long period (2006-2016). The paper focuses on determining the reason for this trend using the similar systems technique, finding that the armed conflicts that have occurred since the second half of the twentieth century may possibly offer an explanation.

Keywords: democracy, rural, terrorism, Bolivia, Ecuador, Peru.

\section{Resumo:}

No que respeita à democracia nas zonas urbanas e rurais, as ciências sociais tenderam a relacionar a democracia ao desenvolvimento da urbanização. Desde diferentes abordagens (institucionalista, culturalista ou historiográfica) foi estabelecida uma linha comum entre a urbanização e o apoio à democracia. No entanto, neste documento, com base na análise dos países andinos centrais, foi possível descobrir que no Equador e na Bolívia foram as zonas rurais que demonstraram maior apoio ao sistema democrático em comparação com o Peru durante uma década (20062016). O objetivo deste documento centra-se na resolução da razão desta tendência através da técnica de sistemas semelhantes, descobrindo que o fenômeno dos conflitos armados que têm ocorrido desde a segunda metade do século XX é uma possível condição explicativa.

Palavras-chave: democracia, rural, terrorismo, Bolívia, Equador, Peru. 


\section{Introducción ${ }^{1}$}

El 2019 fue un año significativo y tenso para la democracia de los países andinos centrales. Durante unas horas, en Perú, la disolución de la cámara legislativa por parte del presidente Martín Vizcarra, en septiembre de ese año, llevó a que en el territorio conviviesen en simultaneo dos jefes de estado, lo que generó un contexto de incertidumbre constitucional. En Ecuador, el ejecutivo de Lenin Moreno se vio obligado al retiro del equipo de gobierno fuera de la capital, ante la oleada de protestas que tuvo su origen en el alza a los subsidios de los combustibles y que condujo a la ocupación de las principales sedes gubernamentales durante octubre. El caso de Bolivia fue el más importante, dado que en el mismo mes de octubre se dio la salida del país del presidente Evo Morales ante las acusaciones de fraude electoral. La historia reciente de los tres países se ha visto marcada por la inestabilidad política que han mostrado sus instituciones, algo que ha llevado a analizar el sustento actual del sistema democrático en cada uno de los territorios. Cabe resaltar que, en los últimos años, los mandatarios como Rafael Correa en Ecuador, Ollanta Humala en Perú o el propio Evo Morales en Bolivia recibieron el apoyo desde las áreas rurales. Sin embargo, la relación entre zonas rurales y democracia no se ha visto exenta de crítica dentro de las ciencias sociales.

El inicio y el desarrollo del sistema democrático con todas sus variantes ha tendido a ser situado en el seno de las urbes. Por ejemplo, dentro del marco de las ciudadesestado griegas, H. Laski afirmaba que la organized democracy era producto de la vida urbana (aunque con una concepción de ciudadanía limitada) la cual procedía o surgía como consecuencias de las relaciones comerciales de ultramar como fue el caso de Atenas (1935, p. 78). La identificación de ambos conceptos o el que se haya asociado la democracia a la urbanización, ha sido una constante en las ciencias sociales desde distintas perspectivas. En contrapartida, si la democracia ha mantenido una identificación en tanto apoyo u origen con las zonas urbanas, las áreas rurales fueron identificadas con un escaso apoyo a la democracia. No obstante, esta identificación no viene dada per se, ya que ejemplos no han faltado. Un caso emblemático fue el apoyo electoral recabado por parte del nacional-socialismo de Hitler, donde la mayor parte de los votos provinieron de comunidades pequeñas y de las zonas rurales en 1933 (Lipset, 1959).

A partir de lo expuesto, este trabajo ha analizado el apoyo de las zonas rurales al sistema democrático en los países andinos centrales (Bolivia, Ecuador y Perú) a partir de la Encuesta del Barómetro de las Américas, LAPOP, durante una década (2006-2016) y ha podido obtener evidencia que, en dos de ellos (Bolivia y

1. Los comentarios de Fabiola Mota Consejero fueron fundamentales para el desarrollo de esta investigación, mi eterna gratitud hacia ella. El contenido del artículo es responsabilidad única del autor. 
Ecuador), las áreas rurales han apoyado en mayor medida el sistema democrático antes que las zonas urbanas. La investigación se ha centrado en explicar cuáles han podido ser las causas de este resultado. Es así que, a partir de la técnica de sistemas similares del método comparativo, la hipótesis propuesta para explicar este fenómeno se ha centrado en el impacto de los conflictos armados, que en el caso peruano se dio principalmente en las zonas rurales y quebró todo ordenamiento social y político, lo que llevó a una inoperancia de la sociedad civil incapaz de sostener los valores democráticos. Esto no existió en mismo grado en Bolivia ni Ecuador.

El trabajo se ha estructurado en cuatro partes. En la primera sección se expone el marco teórico donde se hace referencia a la relación entre zonas rurales y democracia, así como a la literatura en torno a la hipótesis propuesta. La segunda parte apunta a la definición de los conceptos de zonas/áreas rurales y al de democracia, a la par que se observa en detalle cómo ha sido el apoyo en las referidas zonas durante el período señalado. En el siguiente capítulo, se atiende a la metodología utilizada en la investigación y posteriormente se realiza el análisis a partir de la hipótesis señalada en cada caso. Para concluir, en el último apartado se exponen los resultados finales y posteriores consideraciones.

\section{Marco teórico}

El estudio en torno a la relación existente entre democracia y las áreas urbanorurales no es reciente. A partir de la mitad del siglo XX, diversos trabajos ya habían identificado el rol que jugaba tanto la urbanización como el ámbito rural en el transcurso de las sociedades. Pioneros en este asunto fueron los autores de la denominada Teoría de la Modernización tales como Seymour Lipset, Jacques Lambert, Samuel Huntington, Gabriel Almond y Sidney Verba. En síntesis, este enfoque nace como una escuela que pretendía elaborar un marco de análisis para averiguar los mecanismos que podían conducir a un "país tradicional» hacia la modernización social y política, esta última caracterizada por la estabilidad de un sistema constitucional liberal-democrático (Martí i Puig. 2001, p. 105). La Teoría de la Modernización analizaba tal proceso desde dos perspectivas: una centrada en los factores de tipo cultural (donde podemos incluir a Almond y Verba) y un segundo enfoque que hacía énfasis en factores materiales (donde destacan Lambert y Lipset). Dentro del segundo modelo, se pone como una de las bases hacia esa modernización al proceso de urbanización (junto con la industrialización, la riqueza y la educación). Por ejemplo, Lipset (1959) establece la urbanización como índice de desarrollo económico dentro de la hipótesis de la modernización. Como sostiene el autor, el grado de urbanización se relaciona con la coexistencia de la democracia y a través de sus análisis observa que, en una comparativa entre "países más y menos democráticos», los primeros alcanzan 
mayores índices de urbanización que los segundos. Samuel Huntington (1991) otorga un papel especial al ámbito rural, pero desde otro ángulo. Para el autor, la importancia del desarrollo y modernización de las sociedades tradicionales se centra en el fortalecimiento de las instituciones ante la inestabilidad social que conlleva el proceso modernizador. En pocas palabras, elementos como la educación, incremento en las tasas de alfabetización y, para nuestro caso, la urbanización, crean elevadas expectativas que si no se cumplen empujan al conjunto de la sociedad a la acción política; por lo tanto, si las instituciones políticas no son fuertes y no se adaptan ante estos sucesos traerán consigo violencia e inestabilidad (1991, p. 53). Dentro de la organización de los partidos políticos en los países en modernización, la estabilidad está garantizada por las zonas rurales, si no se logra el apoyo del campo en términos electorales no hay posibilidad de estabilidad (1990, p. 382). Ahora bien, la asimilación de los grupos rurales genera que los partidos adapten sus programas en favor de las zonas rurales, cuyos valores son casi siempre muy tradicionales; en consecuencia, la movilización de la mayoría rural para la actividad política por medio del sistema de partidos ejerce un efecto tradicionalizador o conservador sobre la política (1990, p. 389).

En la misma línea, los relatos historiográficos han asociado el atraso político al mundo rural; actualmente, esta idea sobre una magra conexión entre democracia y mundo rural sigue presente entre los muchos historiadores (Herrera y Markoff 2013, pp. 14-15). Así es que, la democracia no es un término que haya sido ligado a las áreas rurales, dado que este sistema político y su tradición histórica han sido identificados con el mundo urbano (Herrera et al, 2013, p. 22). Sucintamente, entre las posibles causas de este fenómeno puede entenderse, en primer lugar, la perspectiva lineal en el estudio de la historia de la democracia (influenciada por la tesis precisamente de la modernización), la cual ha sido entendida como un proceso constante de suma de diversos derechos, reflejo de una lectura jerárquica del concepto de progreso social (Herrera y Markoff, 2013, p. 15). En segundo lugar, la historiografía de tradición francesa que otorgaba un papel pasivo al campesinado, en los procesos de politización del siglo XIX, contribuyó a la idea de democratización unidireccional hacia las masas. Finalmente, gran parte de la literatura en torno al campesinado ha caracterizado a este actor colectivo por el uso de estrategias de lucha alejadas de fórmulas democráticas, lo que ha generado una visión de sujeto abocado al radicalismo (2013, p. 16).

Desde una perspectiva centrada en el aspecto cultural, también se ha hecho hincapié en la existencia de signos autoritarios en las clases obreras. Precisamente, para el caso latinoamericano, Mansilla (2016) ha puesto la atención sobre la existencia de una cultura autoritaria en la zona rural-andina. El autor fundamenta esta idea sobre la base de la propia estructura de las familias andinas rurales, la cual ha 
generado que sean proclives a la violencia de todo tipo. De igual manera, para el caso del impacto del grupo armado Sendero Luminoso, Bernales, a la hora de preguntarse el motivo por el que su discurso impactó en el campo peruano, anota como posibles respuestas el legado autoritario de estos sectores, la belicosidad de gran parte de las comunidades campesinas, así como el pensamiento milenarista de la civilización aborigen (Bernales, 1985, pp. 68-70).

En lo referente a los estudios que han centrado su atención en la teorización de la legitimidad democrática, el trabajo de Booth y Selgison (2009) ha mostrado una estructura completa en este sentido. A partir de las investigaciones de Norris (1999) y Dalton (1999), que a su vez se basan en la distinción entre el apoyo difuso (centrado en el apoyo al sistema en su conjunto) y el apoyo específico (que concierne al apoyo a instituciones o gobernantes en concreto) hecha por Easton (1975), aquellos autores han propuesto seis dimensiones de la estructura de la legitimidad política en un estudio de ochos países: la legitimidad democrática se compone de diversos niveles de apoyos (apoyo a los principios democráticos en tanto régimen, apoyo al gobierno a nivel local, apoyo a la comunidad política, apoyo a los actores estatales, apoyo al desempeño de las autoridades y el apoyo a las instituciones) conformando una visión multidimensional del concepto de legitimidad (Booth y Selgison, 2009). Si bien es cierto que no se hace referencia de forma directa al eje urbano-rural, parte de los resultados (obtenidos de los modelos estadísticos propuestos) muestran que existe una predisposición positiva a algunas de las dimensiones señaladas, lo que pone en entredicho las identificaciones antidemocráticas o el disengaged de la política que distintas investigaciones habían sostenido previamente (2009, p. 124).

Con relación al sustento teórico de la hipótesis, la cual versa sobre (H1), cómo los conflictos armados afectan a las prácticas democráticas, varios trabajos han sugerido que el terrorismo tiene un efecto sobre el plano político (entre otros tantos como en el apartado económico o el psicológico), concretamente sobre el comportamiento electoral en aquellos casos donde se han desatado fenómenos de este calibre (desde la conformación de grupos armados hasta actos puntuales). ${ }^{2}$ Un ejemplo preciso son los atentados del $11 \mathrm{M}$ en Madrid (España) donde autores como García Montalvo (2007) o Chari (2004) argumentan que las explosiones en el sistema ferroviario madrileño marcaron las elecciones que en esa misma semana se celebraban, donde el Partido Popular (formación que, según las encuestas, volvería a dirigir una nueva etapa de gobierno) perdería finalmente las elecciones frente al Partido Socialista Obrero Español (segundo en los mismos sondeos).

2. Aunque la teoría sobre el terrorismo diferencia entre el terrorismo transnacional y el doméstico sobre todo en lo que respecta al tema de causas y orígenes al igual que la estrategia para enfrentarlo, en este escrito nos enfocamos en sus consecuencias como por ejemplo las demandas de seguridad por parte de la ciudadanía o, como ya hemos anotado, en el comportamiento electoral. 
De forma similar, en el caso estadounidense para las elecciones presidenciales del 2004, Langer y Cohen (2005) muestran que entre los votantes el terrorismo fue una variante que tomaron en cuenta (la tercera más importante) a la hora de decidir su voto. Existen estudios que también hacen hincapié en el mismo sentido para casos como el de Israel (Berrebi y Klor 2006) donde los conflictos armados influyen en las sucesivas elecciones.

\section{Democracia y división urbano-rural en la región andina central}

En el presente trabajo, la definición de ruralidad se circunscribe en términos de tamaño poblacional. Su puesta en práctica viene justificada en base a que, en primer lugar, ha sido el criterio más utilizado para clasificar los tipos de hábitat (Trujillo y Ortega, 2015) y, en segundo lugar, las instituciones/agencias estatales destinadas al análisis y a la descripción poblacional utilizan la diferenciación entre lo urbano y rural en términos censales. No obstante, cabe puntualizar que tal referencia no está exenta de discusión. Si bien los criterios de población siguen siendo hasta el día de hoy la base para la clasificación de lo rural y urbano, desde principios del siglo XX ya se habían señalado las limitaciones de uso de este indicador (Wirth, 1938; citado en Trujillo y Ortega, 2015). Actualmente, la misma crítica sigue presente cuestionando su capacidad explicativa (Herrera et al, 2013); para el caso latinoamericano (en especial Chile y Perú) el mismo cuestionamiento está presente si atendemos las observaciones de Werner Melgar $(2008 ; 2011)$ sobre cómo los países de esta región toman diferentes criterios en el conteo poblacional en el momento de censar sus diversos ámbitos, tanto así que, según estimaciones del Banco Mundial, la población rural para el año 2008 podía ser el doble de lo que se señalaba.

Teniendo en cuenta este panorama, los datos que se han recogido para esta investigación corresponden a los distintos censos nacionales llevados a cabo por los tres países (Cuadro 1). El ámbito rural peruano se sitúa en un 20,7\% del total de la población, Ecuador presenta un 25,7\% de población rural y Bolivia un 32,5\% en el mismo sentido. Según los mismos datos, tanto Bolivia como Perú definen las zonas rurales como centros poblados de menos de dos mil habitantes de forma no aglomerada, mientras que para el caso ecuatoriano, las áreas periféricas, los núcleos urbanos y las poblaciones dispersas, responden a la clasificación política de «parroquias rurales». 
Cuadro 1. Población urbano-rural de los países centrales andinos

\begin{tabular}{ccc}
\hline & Urbano (\%) & Rural (\%) \\
\hline Bolivia & $6788962(67,5 \%)$ & $3270894(32,5 \%)$ \\
Ecuador & $10761239(74,3 \%)$ & $3722259(25,7 \%)$ \\
Perú & $23311893(79,3 \%)$ & $6069991(20,7 \%)$ \\
\hline
\end{tabular}

Fuente: INE (2012), INEC (2010) e INEI (2017)

Si nos centramos en lo referente a lo que se entiende por democracia en este estudio, su definición parte de las encuestas de LAPOP que hemos utilizado para nuestras observaciones. Una de las preguntas que propone (y que aparece en encuestas similares como puede ser el Latinobarómetro) a los entrevistados es «con cuál de las siguientes frases está usted de acuerdo: (1) a la gente como uno, le da lo mismo un régimen democrático que uno no democrático; (2) la democracia es preferible a cualquier otra forma de gobierno; (3) en algunas circunstancias un gobierno autoritario puede ser preferible a uno democrático y (4) NS/NR». ${ }^{3}$ La cuestión señalada define la democracia en términos de apoyo o rechazo al sistema democrático caracterizado por un determinado contexto en la región andina central en la que destacan aspectos fundamentales como la celebración de elecciones libres, el derecho al sufragio activo y pasivo, la separación de poderes, derecho a la información o la existencia y el rol de los partidos políticos en la oposición. Este no es el lugar para desarrollar una discusión acerca de la evolución del concepto de democracia, no obstante, las características mostradas coinciden con la propuesta de Robert Dahl (1989) en torno al concepto de "poliarquía», a partir de la cual se han desarrollado diferentes trabajos para los países andinos y Latinoamérica (Tanaka, 1998; Dargent, 2011; Pachano, 2012).

Con esta propuesta conceptual pasamos al análisis cronológico del apoyo en los sectores urbanos y rurales en referencia al sistema democrático ${ }^{4}$. Si nos fijamos en estas diferencias a nivel nacional (Gráficos 1.1, 1.2 y 1.3), se puede visualizar que ante la pregunta a la cual hacíamos referencia anteriormente respecto al apoyo al sistema democrático, desde el 2006 hasta el 2014 en Ecuador y Bolivia los sectores rurales han mostrado un apoyo superior frente a las zonas urbanas

3. En las encuestas esta pregunta se identifica mediante el código DEM2

4. Si bien es notado, no se realiza un análisis a nivel multidimensional en línea con los estudios comentados previamente, dado que el trabajo se centra exclusivamente en la observación de las partes rurales frente a las áreas urbanas. Lo que se pretende es dar una mirada hacia el apoyo al régimen democrático en términos de apoyo difuso. No se puede negar la carencia de concurrir por una sola perspectiva, sin embargo, es útil conocer el nivel de preferencia de estas zonas que se tiene de la democracia independientemente del sentido que se le otorgue al término (Monsivais-Carrillo, 2020, p.155). 
en contrapartida de lo que ha venido sucediendo en Perú, cuyo apoyo es inverso, las áreas urbanas son las que registran mayor respaldo al sistema democrático. ${ }^{5}$

Gráfico 1.1. Apoyo a la democracia por áreas en Ecuador (2006 - 2014)

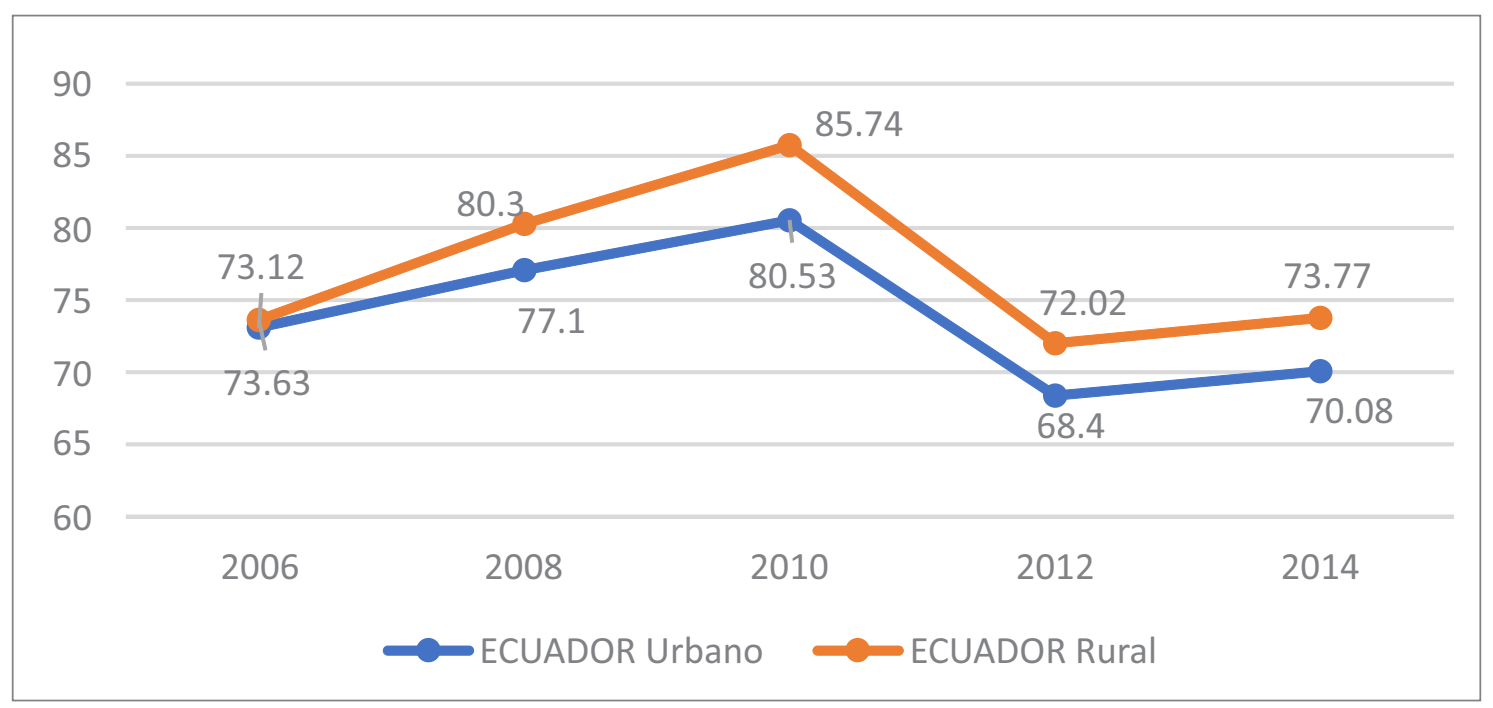

Fuente: LAPOP

Gráfico 1.2. Apoyo a la democracia por áreas en Bolivia (2006 - 2014)

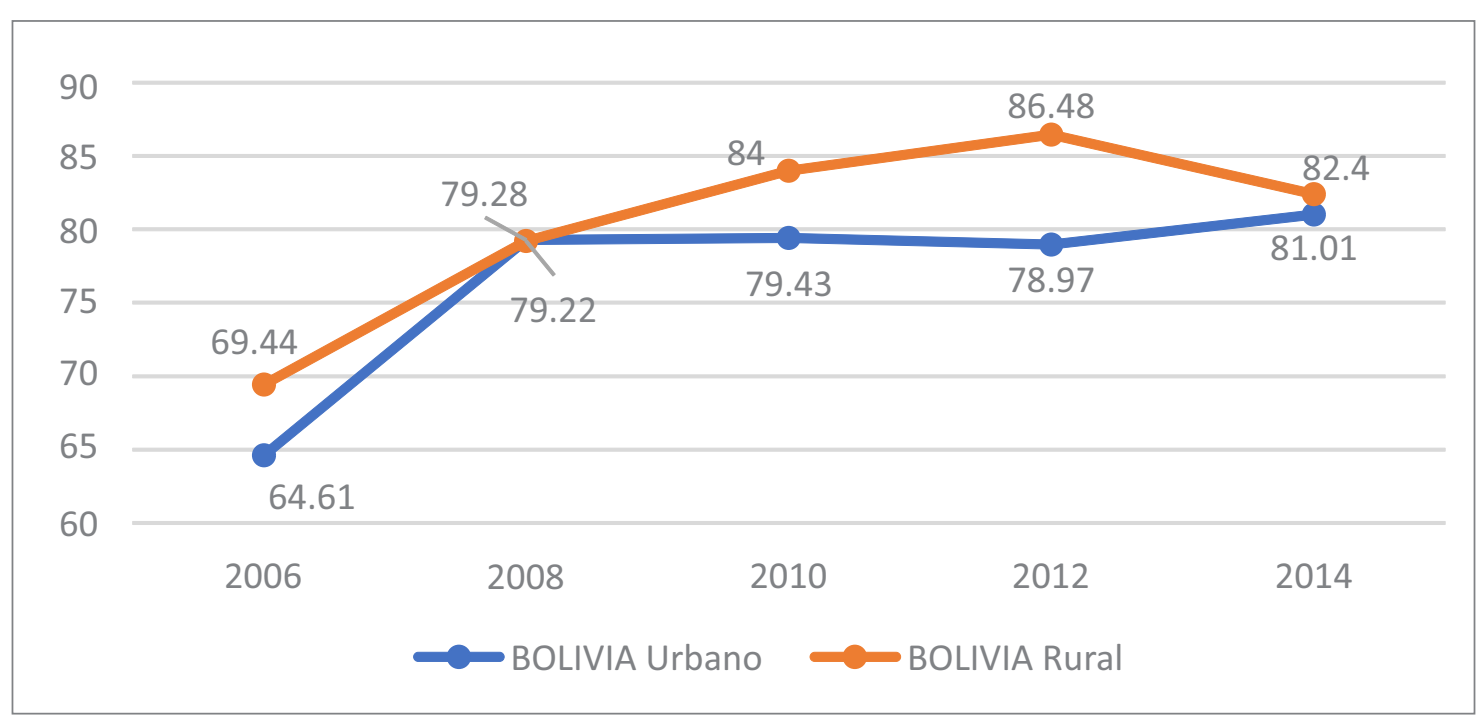

Fuente: LAPOP

5. Para el resultado y representación de los gráficos se ha tomado como una misma categoría las opciones (1) «a la gente como uno, le da lo mismo un régimen democrático que uno no democrático» y (3) «en algunas circunstancias, un gobierno autoritario puede ser preferible a uno democrático» frente a la segunda de ellas, la cual indica que «la democracia es preferible a cualquier otra forma de gobierno». La última de las opciones ha sido descartada. 
Gráfico 1.3. Apoyo a la democracia por áreas en Perú (2006 - 2014)

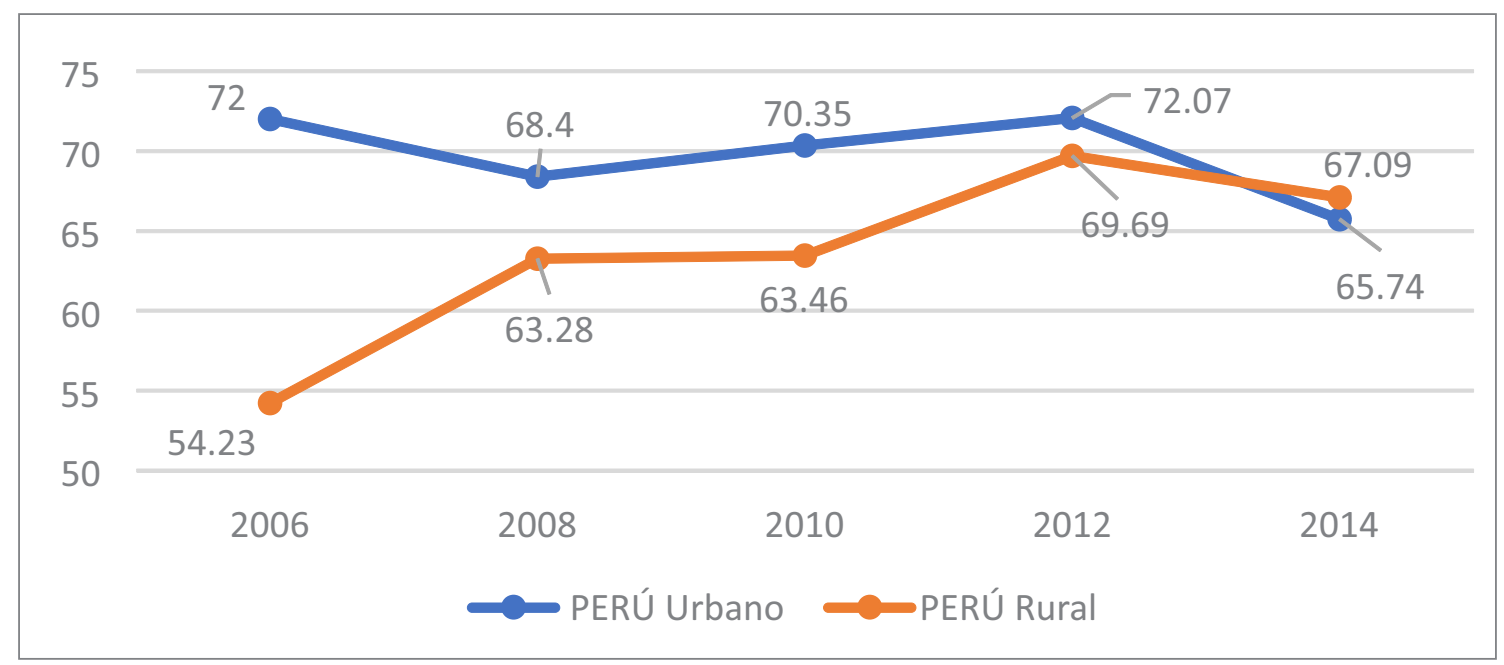

Fuente: LAPOP

La encuesta del Barómetro de las Américas también hace referencia a cuestiones sobre el apoyo a golpes militares, según unas circunstancias específicas ${ }^{6}$. Una de ellas reza sobre un posible golpe militar por una alta percepción de corrupción en el país (del 2006 al 2016). Al observar los casos de Ecuador y Bolivia, para esta pregunta, se puede apreciar que en líneas generales es la parte urbana quien más apoya un golpe militar en ambos países (Gráficos 2.1 y 2.2). Por el lado del caso peruano, la tendencia es inversa y se puede constatar que en la mayoría de los años cuando se realizó la encuesta el sector rural tiene una postura más favorable al apoyo a un golpe militar por las mismas causas (Gráfico 2.3).

Gráfico 2.1. Golpe militar por corrupción por áreas (Ecuador 2006 -2016)

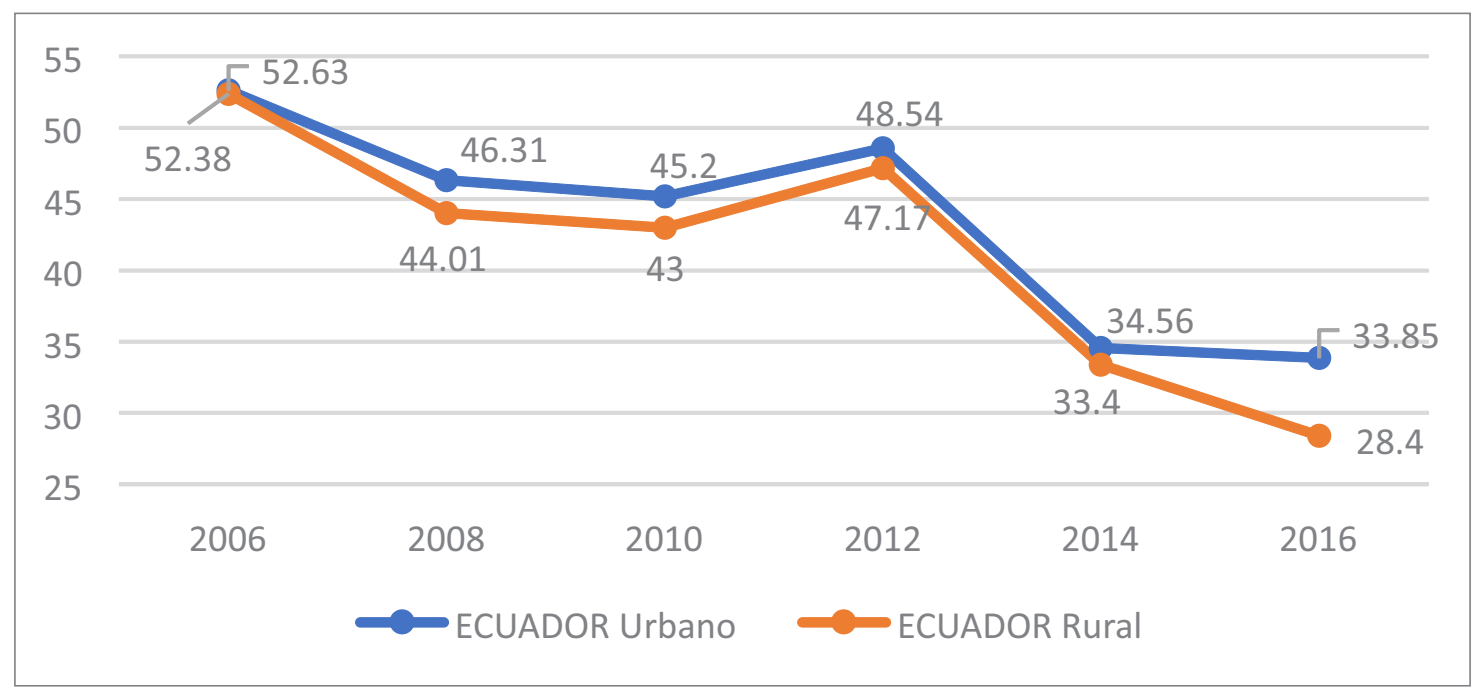

Fuente: LAPOP

6. Dentro de las encuestas del Barómetro de las Américas, puede identificarse las cuestiones en torno a la pregunta sobre la intervención militar en materia de corrupción (la pregunta hipotetiza sobre distintas coyunturas) mediante el código JC13. 
Gráfico 2.2. Golpe militar por corrupción por áreas (Bolivia 2006 -2016)

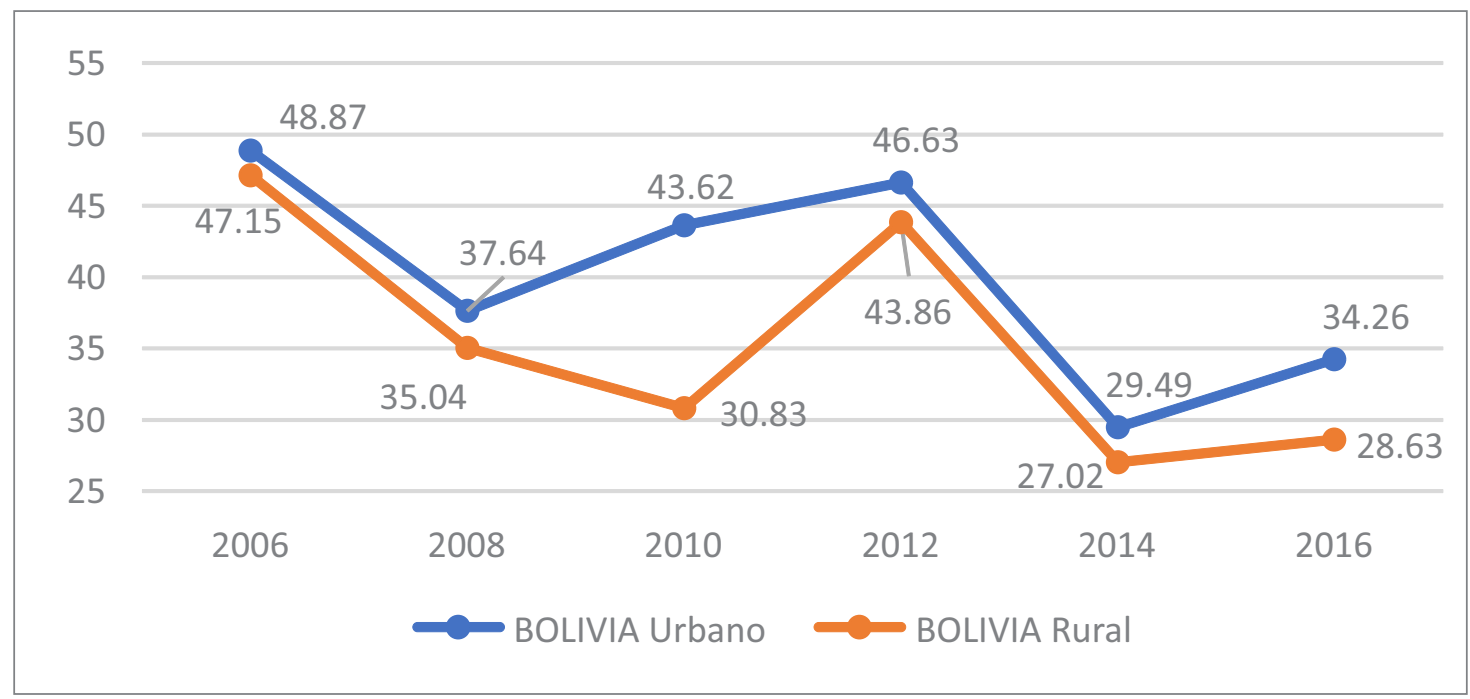

Fuente: LAPOP

Gráfico 2.3. Golpe militar por corrupción por áreas (Perú 2006 -2016)

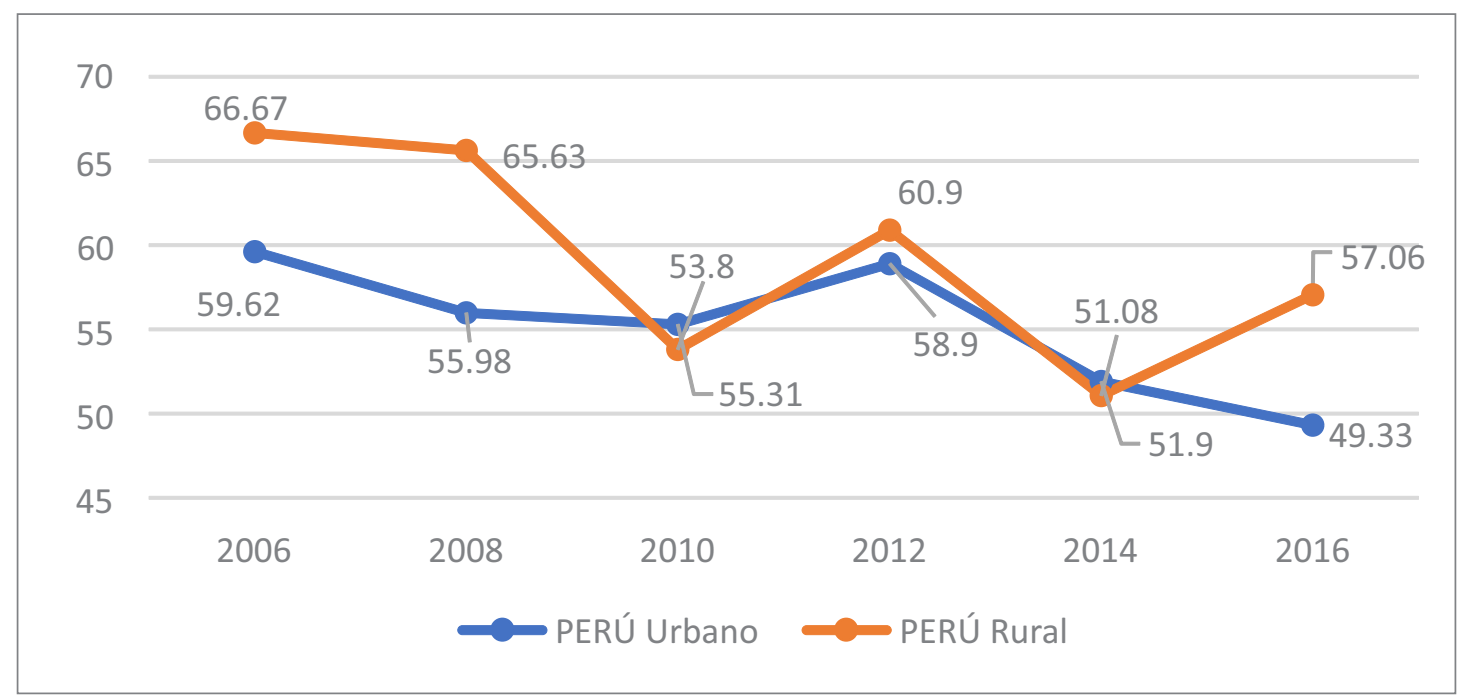

Fuente: LAPOP

Con todo ello, observada una tendencia contraria a la literatura expuesta, dicho análisis amerita la propuesta de condiciones explicativas sobre las posibles causas y respuestas de estas tendencias en los países andinos centrales. A partir de este punto, nuestra hipótesis se ha centrado en:

(H1) las consecuencias de la acción armada entre los grupos subversivos y el Estado, que provocó la destrucción de la sociedad civil en las zonas rurales imposibilitando el desarrollo de prácticas democráticas. 


\section{Análisis comparativo de las diferencias observadas}

La propuesta de análisis se enmarca dentro de la técnica de sistema similares del método comparativo. Al igual que comenta Caïs $(1994$, p. 29) lo que se trata de resolver es una paradoja: varios sistemas son iguales o similares, pero se obtiene un resultado diferente, lo que precisa la identificación de aquella variable (o variables) que explique el resultado distinto. En nuestro análisis, la variable dependiente refleja el fenómeno a explicar que concierne al apoyo o no de las zonas rurales al sistema democrático, mientras que la variable explicativa (X1) representa nuestra hipótesis que da cuenta de la incidencia (baja o alta) del conflicto armado entre el Estado y grupos subversivos. Pueden presentarse numerosas variables de control para este estudio (VCx), no obstante, y por razones de espacio, en este trabajo se han seleccionado aquellas que pueden dar respuestas a través de ámbitos como el económico o el institucional.

Cuadro 2

\begin{tabular}{cccc}
\hline & Bolivia & Ecuador & Perú \\
\hline Rural pro democracia (variable dependiente) & SÍ & SÍ & NO \\
X1 (incidencia de grupos armados) & LEVE & LEVE & ALTA \\
VC1 (situación económica) & Similitud & Similitud & Similitud \\
VC2 (sistema de partidos) & Similitud & Similitud & Similitud \\
\hline
\end{tabular}

** X1 - variable explicativa (hipótesis)

$* * * \mathrm{VCx}-$ variables de control

Por ejemplo, VC1 se enfoca en el aspecto económico. Si nos fijamos en la tendencia regional central andina (Gráfico 3.1), respecto al Producto Interior Bruto (PIB), no se aprecian grandes diferencias ni fluctuaciones desde 1980 hasta 1990. Los tres países mantienen una tendencia similar tanto en los momentos de declive (desde 1984) como en los de crecimiento (desde 1998).

Gráfico 3.1. Países andinos PIB (1980-1990)

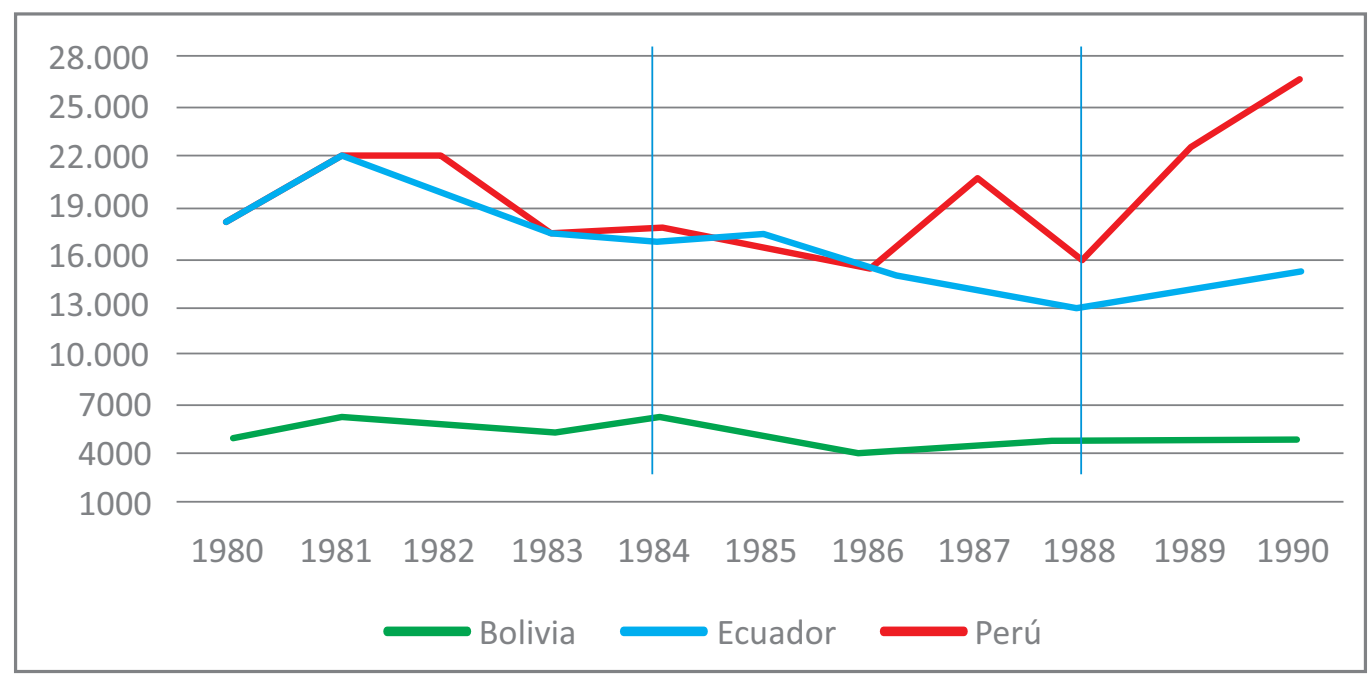

Fuente: Banco Mundial 
Sin embargo, esta apreciación de la tendencia del PIB es a nivel nacional y es necesario observar lo que sucedió a nivel regional, más en concreto en las zonas rurales de los tres países que en este estudio se ha hecho referencia. Para este caso, en vez de una comparativa vía PIB, nos enfocamos en el Índice de Desarrollo Humano Subnacional (SHDI por sus siglas en inglés) ${ }^{7}$. Tal como demuestra el Cuadro 2, en 1991, Bolivia, Ecuador y Perú mostraban similitudes en este ámbito.

Cuadro 3. Índice de Desarrollo Humano Subnacional

\begin{tabular}{cc}
\hline \multicolumn{2}{c}{ Ecuador } \\
\hline Costa & 0.63 \\
Oriente & 0.62 \\
Sierra & 0.65 \\
\hline
\end{tabular}

\begin{tabular}{cc}
\hline \multicolumn{2}{c}{ Perú } \\
\hline Centro & 0.57 \\
Este & 0.55 \\
Sur & 0.64 \\
\hline
\end{tabular}

\begin{tabular}{cc}
\hline \multicolumn{2}{c}{ Bolivia } \\
\hline La Paz & 0.55 \\
Chuquisaca & 0.49 \\
Cochabamba & 0.55 \\
\hline
\end{tabular}

Fuente: Globa Data Lab

Por ejemplo, mientras que las zonas de La Paz, Chuquisaca y Cochabamba mostraban un valor en el IDH de 0,55; 0,49 y 0,47 respectivamente, la zona central (Huancavelica, Huánuco, Junín y Pasco), el este peruano (Cuzco, Puno, Madre de Dios y Apurímac) y la zona sur (Arequipa, Ica, Ayacucho, Tacna y Moquegua) mostraban una media similar: $0,57,0,55$ y 0,64 , respectivamente. Ecuador muestra datos similares, en la Costa (donde se incluye Guayaquil) el IDHS señala un 0,63; la sierra (Quito) marca un 0,65 y la parte Oriental un 0,62.

Para VC2 se ha concretado una variable de corte institucional como el sistema de partidos. En los tres casos, la literatura que hace eco sobre el desarrollo del sistema de partidos muestra que los tres países se han caracterizado por poseer un sistema de partidos no consolidado en la actualidad (Mayorga, 2005; Pachano, 2008; Zavaleta, 2014). Pero décadas atrás, la arena partidaria se encontró con importantes trabas. Desde 1980, en la región andina central, diversos problemas aparecieron dentro de los ejes partidarios como el caso de la volatilidad electoral. Si apreciamos el índice de volatilidad desde finales de los años setenta, nos damos con que la región andina central ocupaba los puestos donde existía una alta volatilidad electoral (Cuadro 4):

7. Los datos mostrados a continuación han sido consultados en Global Data Lab. 
Cuadro 4

\begin{tabular}{ccc}
\hline & Período & $\begin{array}{c}\text { Volatilidad presidencial } \\
\text { y parlamentaria (\%) }\end{array}$ \\
\hline Uruguay & $1971-89$ & 9,1 \\
Colombia & $1970-90$ & 9,7 \\
Costa Rica & $1970-90$ & 16,3 \\
Chile & $1973-90$ & 16,5 \\
Venezuela & $1973-93$ & 18,8 \\
Argentina & $1983-93$ & 20 \\
México & $1982-91$ & 27,3 \\
Paraguay & $1983-93$ & 31,4 \\
Bolivia & $1979-93$ & 36,1 \\
Ecuador & $1978-92$ & 37,9 \\
Perú & $1978-90$ & 54,2 \\
Brasil & $1982-90$ & 70 \\
\hline
\end{tabular}

Fuente: Tanaka (1998)

Como se aprecia, la región andina se situaba a la cola en torno al índice de volatilidad frente a países como Uruguay, Chile o Costa Rica, por lo tanto, la parte andina presentaba una línea común entre sus miembros, pero bastante diferenciada del resto de países del continente.

En definitiva, las variables de control muestran que el caso peruano estaba acorde con sus pares andinos; en ese sentido, surge la necesidad de encontrar una explicación diferente. En otras palabras, debemos buscar una respuesta alternativa que se circunscriba exclusivamente a la realidad peruana como es nuestra propuesta: el conflicto armado.

\section{Lucha armada}

Para dilucidar nuestra hipótesis, la correspondiente operacionalización se ejecuta sobre dos indicadores: las víctimas del proceso armado y los efectos del mismo sobre los procesos electorales en aquellos años. En el primero de ellos se trata de constatar dónde se dio el mayor número de víctimas dentro de los territorios a través de una comparación gráfica (el objetivo es apreciar dónde aparecen las víctimas de los ataques, si en las zonas rurales o urbanas) por parte de la acción armada, tanto de los grupos subversivos así como la respuesta estatal. Con el segundo indicador se pretende corroborar si existe algún tipo de tendencia con relación a las cifras de abstención en las zonas más afectadas por la violencia política en el país. En términos de la elección de los grupos armados, todos ellos se han regido por su impacto social en torno al número de fallecidos y el número de actos. 


\section{Bolivia}

Uno de los actores más importantes, en lo que se refiera a grupos armados en territorio boliviano, fue el Ejército Guerrillero Túpac Katari (EGTK) formado en 1986. Si tomamos como referencia la vuelta a la democracia en Bolivia (1982) hasta la disolución del EGTK (1993), las muertes contabilizadas ante las acciones armadas son un total de al menos cinco víctimas mortales, según la información proporcionada de la Global Terrorism Database (GTD). La línea de acción armada reflejaba que la estrategia político-militar del EGTK intentaba evitar muertes en cada una de sus tácticas dado que las acciones no buscaban la generalización del terror (Jordan Prudencio, 2016, p. 303).

En torno a la acción armada del Estado, en respuesta a los ataques de los grupos subversivos, para el caso boliviano no existe un informe oficial del número aproximado de víctimas (fallecidas o casos de violación de derechos humanos). No obstante, la Asociación de Familiares de Detenidos, Desaparecidos y Mártires por la Liberación Nacional (ASOFAMD) presentó en el 2006 ante la Corte Interamericana de Derechos Humanos (CIDH) un informe sobre el seguimiento de las desapariciones comentadas, que arrojaban la cifra de un total de 154 desaparecidos.

Si pasamos a los datos y a la ubicación de las víctimas en el país, los mapas 1.1 y 1.2 muestran que la mayoría de víctimas perecieron en las zonas más urbanas del país, La Paz y Cochabamba, a excepción de Chuquisaca, una provincia más rural en comparación a las dos primeras, aunque el número de fallecidos en total fue de tres víctimas. Se ha tomado como referencia el año 1982 (restablecimiento del orden democrático) hasta la disolución del EGTK en 1993. Ambos mapas reflejan con claridad que la actuación de los grupos en armas se dio sobre todo en las provincias más urbanas del país antes de desarrollar sus acciones en sectores rurales. Como hemos comentado, los mapas también reflejan la respuesta de las fuerzas gubernamentales y en conjunto también su actuación se circunscribió en esa área. Ello tiene lógica, dado que si los subversivos actuaban en las urbes la contraofensiva estatal arrojaría cifras en estos mismos lugares. 
Mapa 1.1 Provincias urbanas

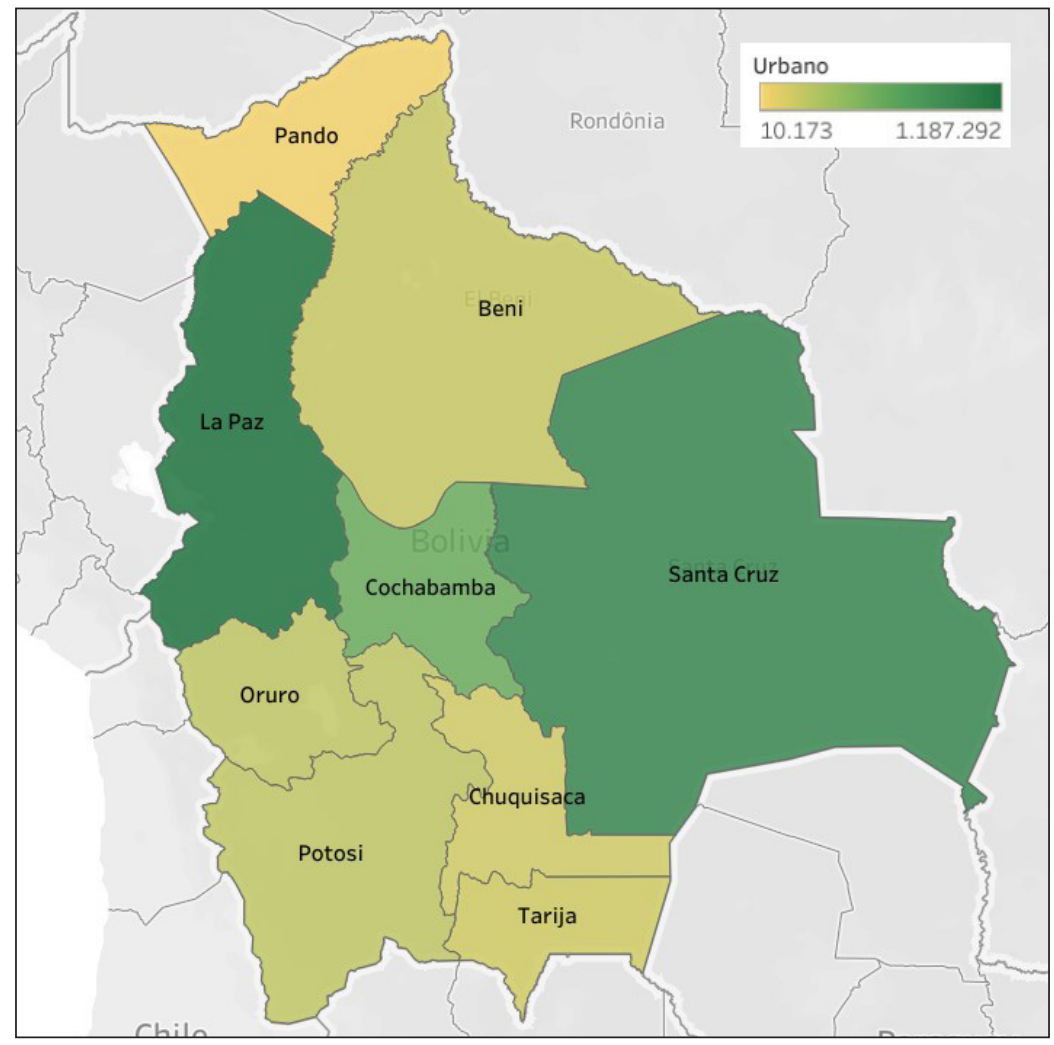

Elaboración propia (Fuente: INE)

Mapa 1.2 Número de víctimas por provincia*

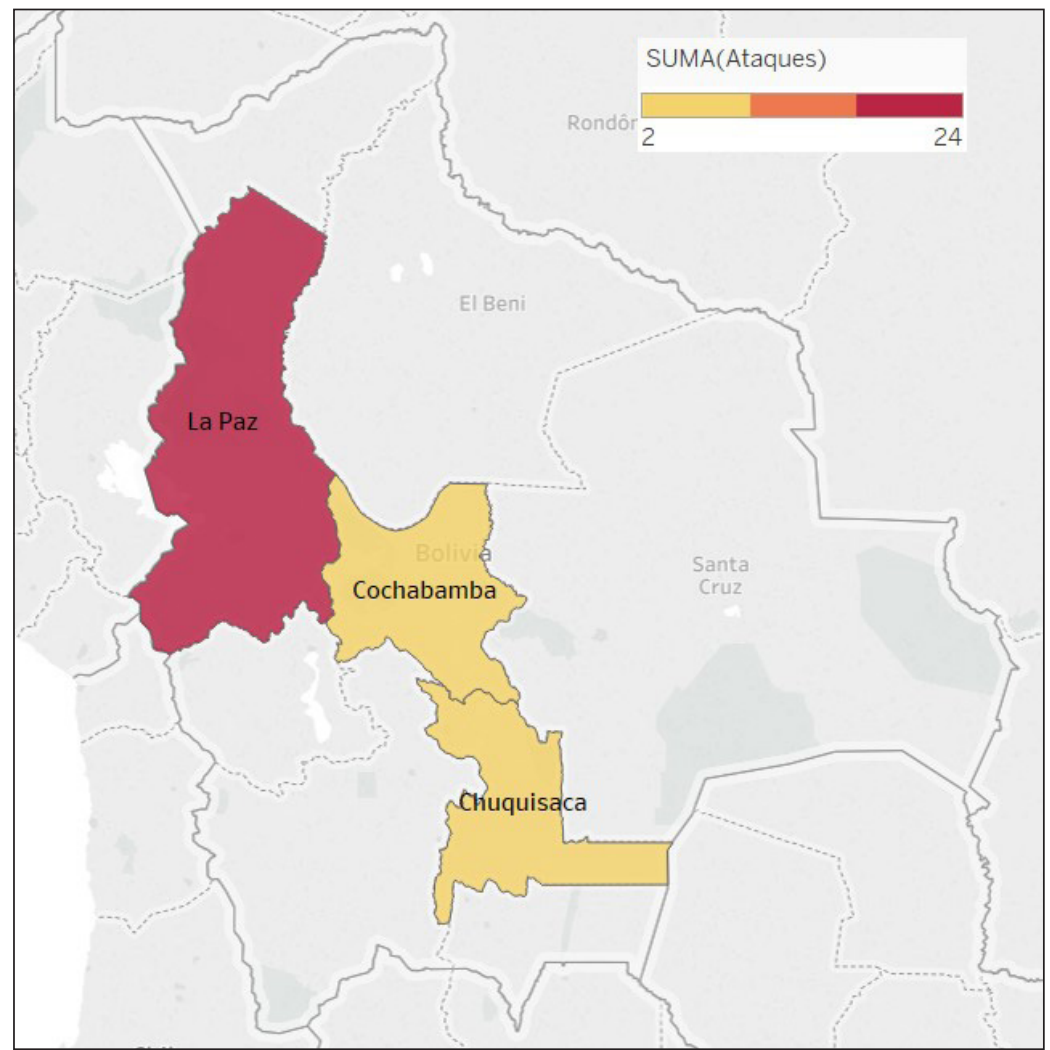

Elaboración propia (Fuente: GTD)

${ }^{\star}$ No incluye número de víctimas de zonas que no han podido ser identificadas 
Enfocándonos en el plano electoral, según la teoría analizada, se había encontrado que, en ciertos casos, el terrorismo y la lucha armada reflejaba sus consecuencias en los diversos procesos electorales. Al igual que el análisis de Lavrard (2009), las cifras de abstencionismo en las elecciones locales pueden aproximarnos al objetivo del trabajo. Además, como han sugerido Pareja Pflucker y Gatti Murriel (1990) es a nivel de las elecciones locales donde la presión terrorista ha desempeñado un papel más importante en cuanto su influencia al comportamiento electoral desde finales de los ochenta. No obstante, cabe resaltar que la abstención puede producirse por otros factores que van más allá de la violencia armada, como es el caso de la falta de interés en la política o variables ligadas a la parte socioeconómica que hacen énfasis en el grado de educación, el nivel de renta o al acceso a la información, entre otras. La medición a través del abstencionismo nos proporciona un dato objetivo y fiable que permite elaborar una comparativa transnacional, dada la escasez de información y datos a nivel regional; por lo tanto, su puesta en marcha se justifica en ambos sentidos para el propósito del trabajo siendo plenamente conscientes de sus limitaciones.

En ese sentido, se ha seleccionado las elecciones municipales de 1991 para el análisis del abstencionismo en el caso boliviano, año en los que el EGTK y otros grupos desarrollaron gran parte de sus acciones. Los datos presentados en la Tabla 1.1 muestran que para 1991 la abstención en las tres ciudades afectadas por el movimiento armado y las fuerzas de defensa estatal tuvieron una abstención relativamente normal en La Paz $(15,4 \%)$ y Chuquisaca $(18,5)$ y bastante alta en Cochabamba (34,5\%). En principio, podría comentarse que, según estos datos, en La Paz y Chuquisaca el posible impacto de la lucha interna fue menor en comparación a Cochabamba donde se llega a un 34,5\% de abstención. Sin embargo, visto en perspectiva comparada respecto a las elecciones de 1987, las cifras no difieren tanto las unas de las otras en las mismas provincias y de hecho son menores que estas: La Paz 18,9\%, Chuquisaca con 23,2 \% de abstención y Cochabamba con una cifra alta, pero similar a la de 1991 con 41,2\%; por lo tanto, no puede hablarse de un indicio en torno a estas cifras (sobre todo en el caso de Cochabamba) a la hora de situar al conflicto armado como una posible variante explicativa vista esta breve serie histórica. ${ }^{8}$ De la misma forma, si observamos la abstención en conjunto, la media nacional en ambos procesos se sitúan dentro de los valores señalados. En 1987, la abstención en todo el territorio fue del 29,12\%, mientras que para las elecciones de 1991 se sitúo en un 19,69\%.

8. No se han introducido los datos correspondientes a las elecciones municipales de 1989 y 1985 , ya que los datos recogidos por el ente electoral boliviano (OEP) no reflejan el número de electores inscritos para ambos procesos. En cuanto a la omisión de las elecciones de 1993 en este caso, su celebración se dio una vez que gran parte de los miembros del EGTK habían sido capturados y cuyo penúltimo ataque en esos años fue en noviembre de 1992. 
Tabla 1.1. Abstención Elecciones Municipales (\%)

\begin{tabular}{ccc}
\hline Provincias & 1987 & 1991 \\
\hline La Paz & $18,9 \%$ & $15,4 \%(-3,5)$ \\
Chuquisaca & $23,2 \%$ & $18,5 \%(-4,7)$ \\
Cochabamba & $41,2 \%$ & $34,5 \%(-6,7)$ \\
\hline
\end{tabular}

Fuente: Órgano Electoral Plurinacional

\section{Ecuador}

Para el contexto del Ecuador, una de las guerrillas más destacables fue la organización Alfaro Vive Carajo (AVC), la cual estuvo vigente desde 1983 hasta su disolución en 1991. Según cálculos de Jiménez y Franchi (2016), el grupo cometió un total de ochenta y cuatro ataques entre aquellos años sobre todo en ciudades como Quito y Guayaquil. El saldo total de fallecidos asciende a 16 personas, según la base de datos de la Global Terrorism Database (GTB). Bajo el período de Febres Cordero (1984-1988), según el informe de la Comisión de la Verdad (2010), se constató un total de 310 víctimas que sufrieron desde desapariciones forzadas, ejecuciones extrajudiciales o torturas, entre los que se encontraban los miembros de AVC.

En consecuencia, al igual que la experiencia boliviana, analizamos el impacto subversivo a través de las diferentes provincias del país. Tal y como se aprecia en los mapas 2.1 y 2.2 , la mayor parte de las víctimas se centraron en los espacios menos rurales, especialmente en dos de las ciudades más importante del país: la capital Quito (Pichincha) y Guayaquil (Guayas). Como se aprecia, el territorio de Guayas fue el más afectado por las disputas entre ambos actores (el total de víctimas fue de 146) seguido por la Provincia de Pichincha con casi 100 afectados. Loja y el Oro son otras de las zonas donde hubo un numero alto de víctimas en el fuego cruzado (66 y 71 respectivamente); el resto de las provincias señaladas en el Mapa 2.2 muestran cifras inferiores respecto de las primeras (Azuay con 17 afectados, sobre todo en la ciudad de Cuenca, la provincia de Esmeraldas con 26 casos de violaciones de derechos humanos, y Sucumbios con 24 casos).

Si pasamos al plano electoral y nos centramos en los procesos locales, para Ecuador hemos analizado las elecciones de concejales municipales $(1980,1984,1986$ y 1988). Consideramos que las elecciones clave respecto a una posible repercusión de los disturbios son las del año 1986, dado que en ese año se reportaron siete atentados con una cifra de trece fallecidos (principalmente en la ciudad de Quito), además del resto de sucesos que ya venían ocurriendo un año antes con idéntico número de acciones, aunque sin haber perdido vidas humanas. Se ha tomado también las elecciones posteriores de 1988 principalmente porque, si bien la banda armada a partir de 1986 recae en el número de atentados además de la muerte de unos de sus 
Mapa 2.1 Porcentaje de población rural por cantón*

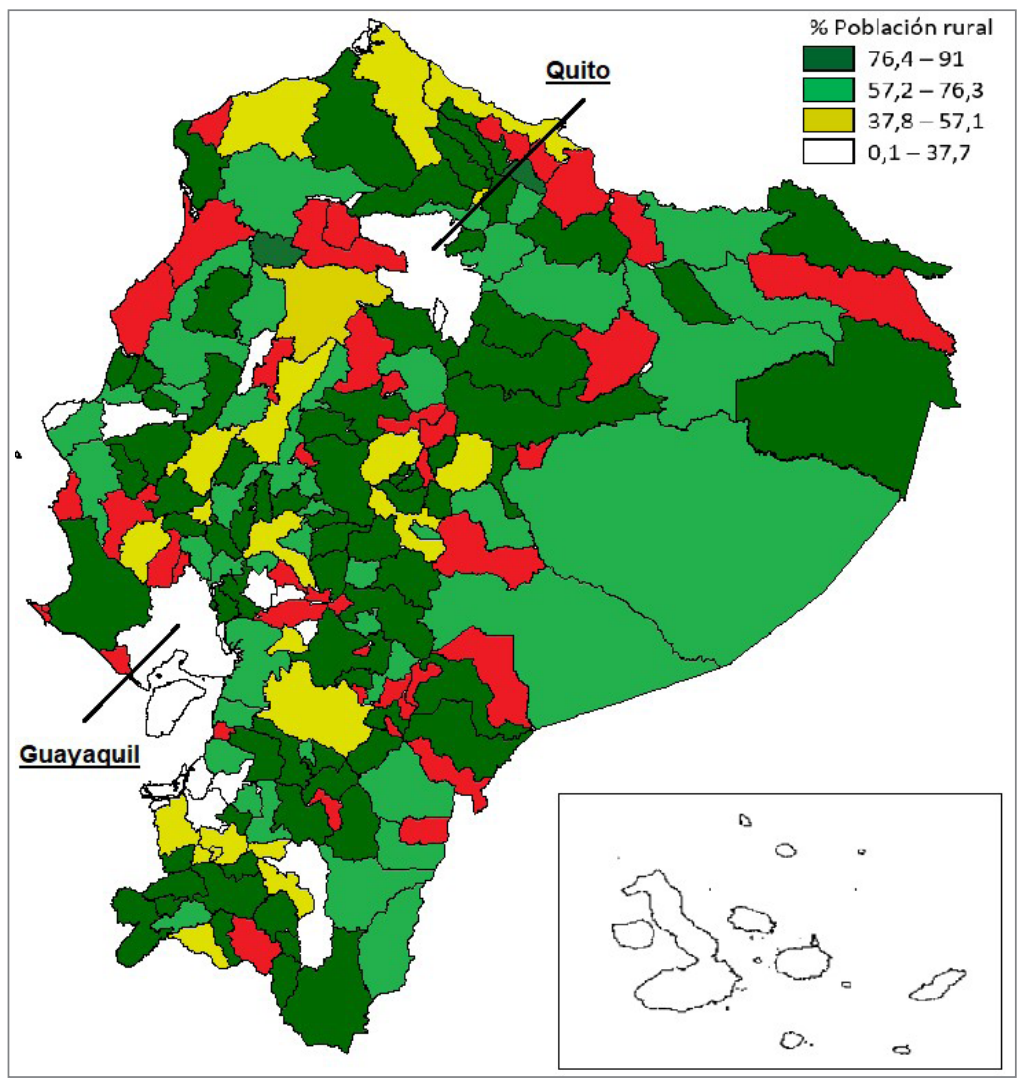

Elaboración propia (Fuente: INEC)

${ }^{\star}$ Los datos en rojo muestran zonas que para el censo de 1992 no estaban constituidas.

Mapa 2.2 Número de víctimas por cantón

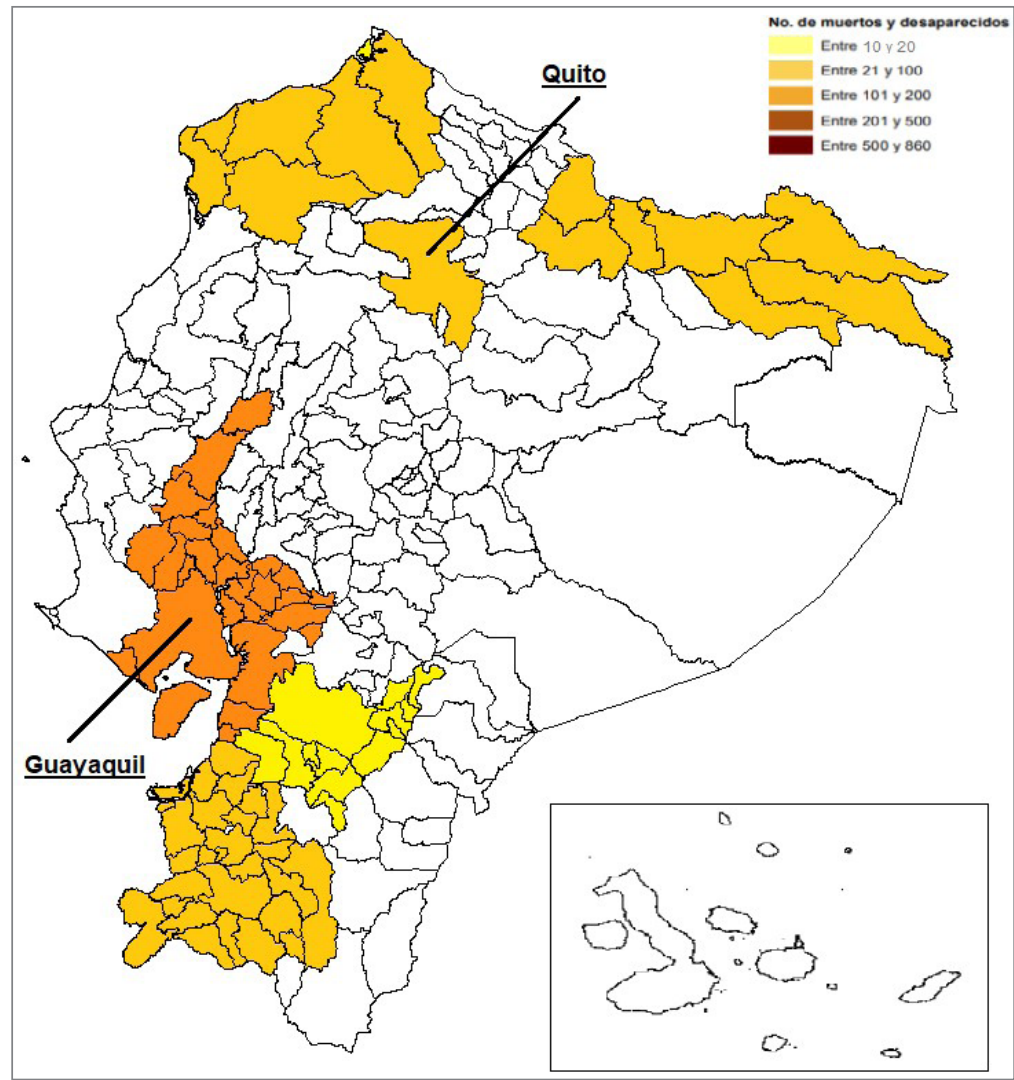

Elaboración propia (Fuente: GTD) 
líderes, entre 1987 y 1988 sucedieron tres ataques más (en paralelo a las elecciones de ese mismo año). ${ }^{9}$

Como se puede ver en la Tabla 2.1, en esta se refleja la abstención en las elecciones a los concejales municipales, el historial en este apartado no presenta variaciones tan pronunciadas y la tendencia ha sido decreciente desde 1984 para todas las provincias, salvo en un único caso (en las elecciones de Loja en 1986 con una subida mínima del $0,2 \%$ de abstención). Las cifras en torno a la media nacional de la abstención tampoco presentan números tan dispares en cada una de las provincias: $27,1 \%$ en $1980 ; 28,73 \%$ en $1984 ; 26,07 \%$ en 1986 y $22,96 \%$ en las elecciones de 1988. Todo ello sugiere que, en paralelo a los datos de Bolivia, no se puede anotar a través de la abstención cambios significativos en la participación ciudadana tras los atentados de aquellos años.

Tabla 2.1. Abstención elección concejales municipales por provincias (\%)

\begin{tabular}{ccccc}
\hline Provincias & 1980 & 1984 & 1986 & 1988 \\
\hline Pichincha & $26 \%$ & $26,46 \%$ & $23,79 \%(-2,6)$ & $19,66 \%(-4,1)$ \\
Guayas & $25,5 \%$ & $24,75 \%$ & $24,46 \%(-0,3)$ & $21,90 \%(-2,5)$ \\
Loja & $32,28 \%$ & $28,11 \%$ & $28,33 \%(+0,2)$ & $25,26 \%(-3,07)$ \\
El Oro & $29,5 \%$ & $31,76 \%$ & $28,21 \%(-3,5)$ & $22,78 \%(-5,4)$ \\
\hline
\end{tabular}

Fuente: Darlic Mardesic (1989)

\section{Perú}

Junto a países como México o Colombia, Perú ha soportado numerosas experiencias en el plano de los movimientos armados, pero fueron dos los que mayores consecuencias trajeron si tomamos en cuenta el impacto mediático y el número de afectados: el Movimiento Revolucionario Túpac (MRTA) y el Partido Comunista del Perú Sendero Luminoso o simplemente Sendero Luminoso (SL). Según la recopilación dada por la Comisión de la verdad y de la Reconciliación (CVR), al MRTA se le implica el $2 \%$ de los muertos y desaparecidos en la etapa más conflictiva del país (1980-2000).

En cuanto a Sendero Luminoso, el apunte de Alcántara (2013) es bastante preciso en torno a la dinámica de este grupo armado: o se estaba con Sendero o se estaba contra Sendero (p. 516). Las actuaciones de SL han sido calificadas como genocidas y ha sido nombrado como uno de los principales actores responsables de las muertes y desaparecidos en los veinte años que duró el conflicto: se le imputan el $51,4 \%$ de las víctimas, según la CVR.

9. Dos de los mencionados ataques en 1988 por parte de AVC se realizaron cinco días antes de las elecciones seccionales del 31 de enero. 
El gobierno de Belaunde Terry ordenó en 1982 la entrada del ejército a la región de Ayacucho para controlar y militarizar la zona ante la avanzada senderista. Esta medida tuvo una incidencia considerable para la población afectada hasta el final de la guerra interna, ya que al asesinato masivo de campesinos por parte de SL había que sumarle ahora las desapariciones y muertes ejecutadas por el Ejército. Según la CVR, al Ejército peruano se le responsabiliza del 42,9\% del total de los perjudicados en el conflicto.

Si pasamos a nuestro análisis gráfico, podemos observar que, a diferencia de Ecuador y Bolivia, en Perú las acciones se centraron en las zonas rurales antes que en las ciudades más pobladas (ver los mapas 3.1 y 3.2). El balance final de fallecidos durante la guerra interna fue de un total de 69 280, según estimaciones la CVR. Puede verse que Lima (capital) presenta cifras en este sentido con decenas de afectados, sin embargo, regiones rurales como Ayacucho, Apurímac, Junín, Huánuco o Huancavelica superan con creces los números de la capital; por ejemplo, en el departamento de Ayacucho se registró más del 40\% de víctimas y desaparecidos durante toda la etapa armada. Las principales ciudades (situadas en la costa) no estuvieron en el centro del conflicto a pesar de que muchos de los hechos ocurridos tuvieron gran trascendencia en la opinión pública. 
Mapa 3.1 Porcentaje de población rural por provincia

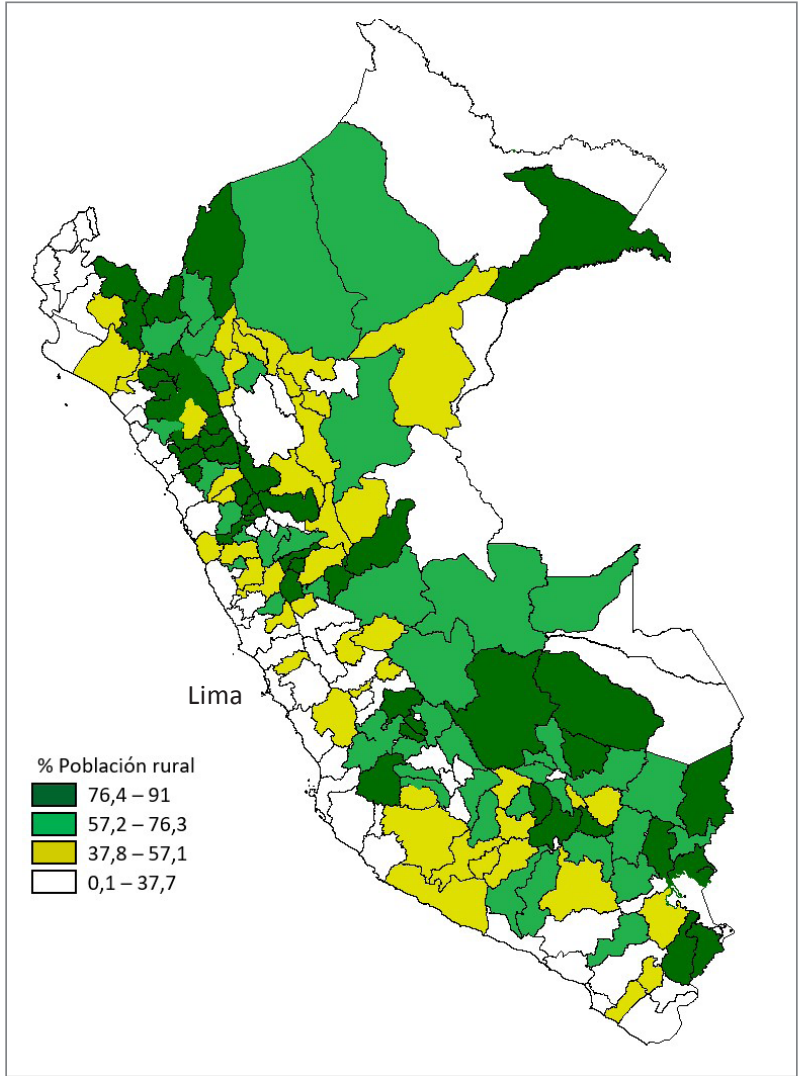

Elaboración propia (Fuente: INEI)

Mapa 3.2 Número de víctimas por provincia*

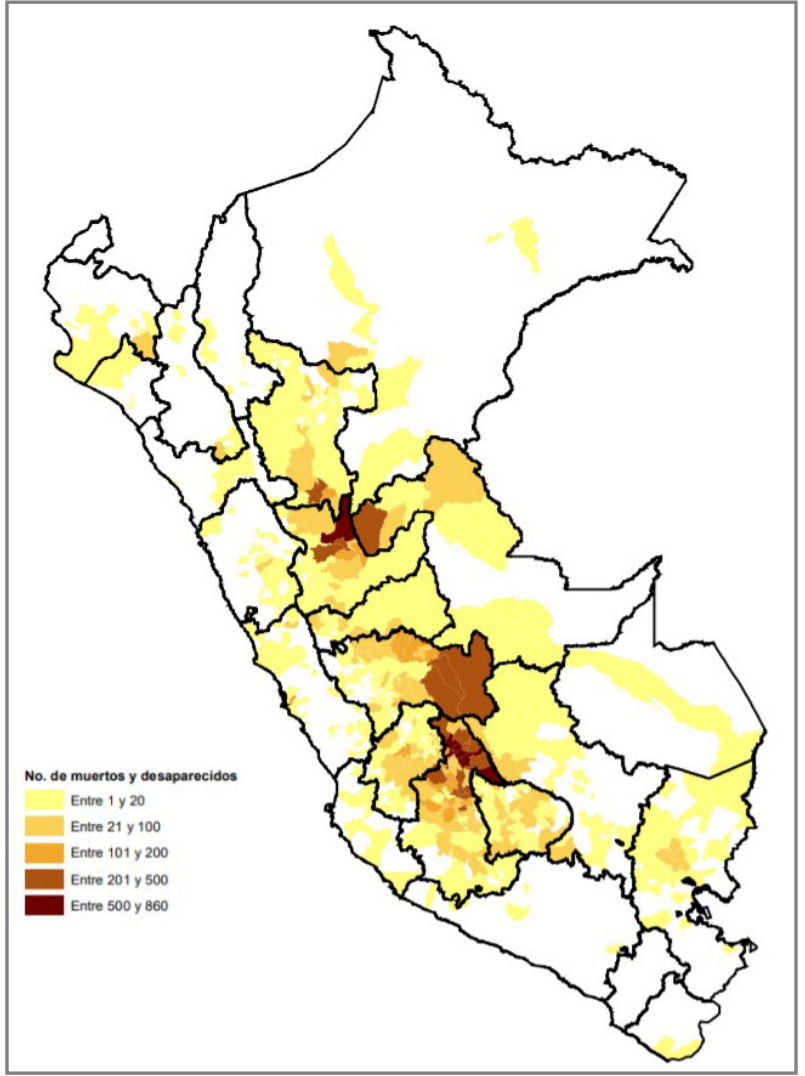

Fuente: CVR (2003) 
A medida que los años avanzaban, las acciones se trasladaron al ámbito urbano, los ataques dejaron de sucederse en las zonas rurales y se centraban más en las ciudades. Ello no significó que en la parte rural el conflicto desapareciese, pero con el tiempo las muertes se redujeron. Esto último podemos apreciarlo en el Gráfico 5, el cual nos será útil a la hora del análisis con las variantes de abstención.

\section{Gráfico 5}

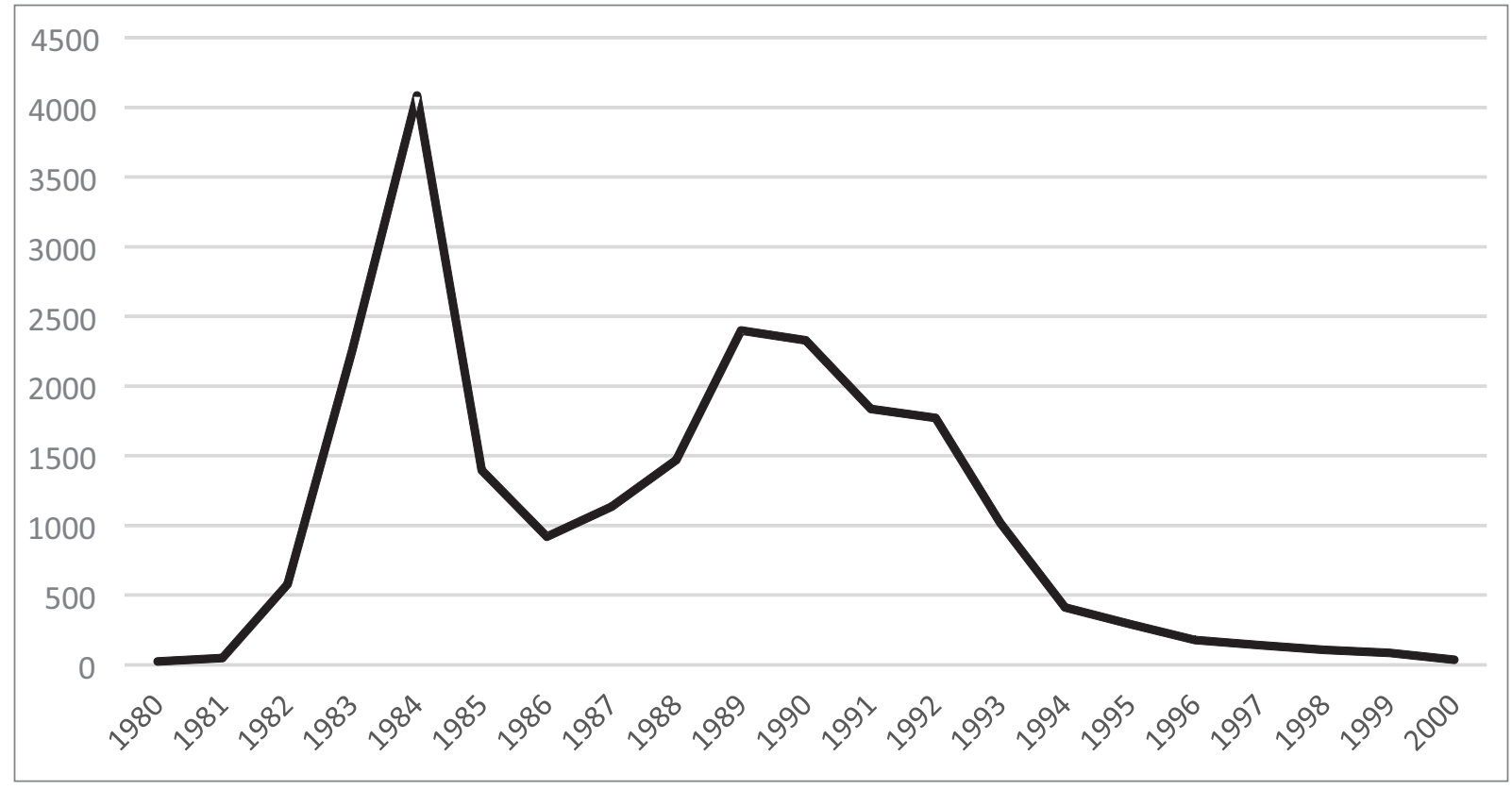

Fuente: CVR (2003)

En el plano electoral, dos van a ser los comicios que se sitúen como eje en este análisis: las elecciones municipales de 1983 y las de 1989, dado que fue durante ambos procesos los momentos donde se dan los picos más altos en cuanto a la relación de muertos y desaparecidos.

Como se puede ver en el Gráfico 5, desde 1982 la violencia aumentó considerablemente alcanzando su punto máximo en 1984 con más de cuatro mil muertes y desaparecidos. En medio de estas fechas se celebraron las elecciones municipales y es preciso ver cuál fue el grado de ausentismo para las elecciones de las autoridades locales. De esta manera, con una abstención del 35,4\% de media nacional para 1983, en las cuatro provincias seleccionadas la diferencia es bastante alta (Tabla 3.1): el mínimo es representado por Apurímac con 44,4\% de ausencias mientras que el máximo es representado por Ayacucho con un $74,8 \%$, es decir, tres de cada cuatro personas se abstuvieron de votar en esas elecciones. Huancavelica y Huánuco no se quedan atrás, la primera tuvo un $48,7 \%$ de abstención y la segunda un $63,4 \%$. 
Tabla 3.1. Abstención elecciones municipales por provincias (\%)

\begin{tabular}{ccccc}
\hline Provincias & 1980 & 1983 & 1986 & 1989 \\
\hline Apurímac & $52,6 \%$ & $\mathbf{4 4 , 4 \% ( - 8 , 2 )}$ & $29,4 \%(-15)$ & $\mathbf{3 8 , 9 \% ( + 9 , 5 )}$ \\
Ayacucho & $52,2 \%$ & $\mathbf{7 4 , 8 \% ( + 2 2 , 6 )}$ & $41,2 \%(-33,6)$ & $\mathbf{5 5 , 8 \% ( + 1 4 , 5 )}$ \\
Huancavelica & $47,8 \%$ & $\mathbf{6 3 , 4 \% ( + 1 5 , 6 )}$ & $38,7 \%(-24,7)$ & $\mathbf{4 5 , 9 \% ( + 7 , 2 )}$ \\
Huánuco & $52,5 \%$ & $\mathbf{4 8 , 7 \% ( - 3 , 9 )}$ & $36,9 \%(-11,8)$ & $\mathbf{5 4 , 5 \% ( + 1 7 , 5 )}$ \\
\hline
\end{tabular}

Fuente: Tuesta Soldevilla (1987); http://blog.pucp.edu.pe/blog/fernandotuesta/datapolitica/

Ahora bien, es cierto que, respecto a las elecciones de 1980, en dos de los casos la ausencia electoral disminuyó. En Huánuco, la abstención se reduce 3,9 puntos porcentuales y en Apurímac un 8,2\%. No obstante, la explicación fundamental se relaciona con que, según el informe de la CVR, entre 1982 y 1985 el conflicto armado interno estuvo circunscrito prácticamente en Ayacucho, mientras que, por ejemplo, en Huánuco, el mayor número de fallecidos se da a partir de 1994 con una escalada importante desde 1986.

Si pasamos a los eventos electorales de 1986, se observa una reducción clara en los niveles de ausentismo en cada una de las cuatro provincias analizadas. Aun con una media nacional de abstención del 21,1\%, estas provincias logran el mínimo histórico desde la reimplementación de las elecciones a nivel local en el país a partir de 1980. Su explicación puede provenir de los datos de nuestro mismo gráfico, donde para 1986 se pasó a un saldo de casi mil fallecidos, frente a los cuatro mil de los años previos por lo que puede representar cierta lógica que, con la baja de los estragos de la guerra interna, la población haya acudido a votar en proporciones más altas. La misma idea está plasmada para las elecciones de 1989, con la creciente tendencia otra vez del número de afectados, los valores en los niveles de abstención vuelven a ascender; para ese año, la media nacional del número de votantes que no acudió a sufragar fue del 30,5\% y los cuatro departamentos superaron el registro nacional. En síntesis, casi por una década, se pueden apreciar una correlación existente entre la abstención y el número de muertos en Apurímac, Ayacucho, Huánuco y Huancavelica.

\section{Análisis final}

Las distintas correlaciones presentadas logran identificar unos resultados singulares respecto a las diferencias entre la parte urbana y la rural. Por lo tanto, las consecuencias de la violencia en lo rural también han podido marcar un desenlace distinto en torno a las prácticas y el sustento de la democracia entre los distintos territorios. Por ejemplo, la CVR (2003, p. 289-299) hace hincapié en mostrar la salida de las autoridades locales, las cuales fueron generadas por los atentados de los grupo armados peruanos, llegándose a una situación de desgobierno donde las comunidades quedaban descabezadas y el nombramiento de autoridades se regía 
por la imposición, ya sea por parte de los militares o por parte de los terroristas dentro de las denominadas «zonas liberadas»; incluso en los momentos en donde se lograba elegir legítimamente a las autoridades, estas quedaban bajo el control de los que poseían las armas. Pero no solo eso, sino que en conjunto los procesos de elección también quedaban desarticulados completamente a causa de la no participación de la población por las mismas causas tal y como se menciona en uno de los testimonios recopilados:

Ya no podía haber autoridades, ya no podía haber candidatos para alcaldes, ya no. Todo el mundo estaba con miedo para ser, para prestar un servicio como alcalde, como gobernador, como juez, como para declararse de tal cual partido. Las elecciones que hubo en ese tiempo había 20 o 30 votos de los que estaban allí, mas arriesgándose, mas. Pero la gente ya no quería saber ya ni de votos ni de partidos, ni de, ni de grupos de ninguna clase, porque el pánico, el miedo era mucho y ya no sé [...] (CVR, 2003, p. 296).

Esta experiencia era palpable desde el principio del conflicto con el ingreso de las fuerzas armadas en 1982. Las continuas proclamaciones de estado de emergencia derivaron en lo que precisa Vergara (2012, p. 177) como Zonas de Emergencia a cargo del Comando Político Militar (CPM), cuyas funciones fueron más allá de lo establecido en torno a la lucha antisubversiva, como la reasignación del presupuesto departamental, algo que estaba completamente fuera de su mando, y por lo tanto de la ley. Recién a partir de 1985 esta situación fue regulada, pero las competencias otorgadas tampoco reflejaban un cuadro democrático. Los CPM tenían ahora la potestad de nombrar, cesar y hasta trasladar a las autoridades civiles, según su criterio y, además, los policías y militares no podían ser juzgados bajo el fuero civil. Ello convirtió a las zonas «resguardadas» en áreas sujetas al mandato castrense sin participación ni control por parte de la sociedad. Llama la atención que aun con la captura de Abimael Guzmán y la caída de SL, la situación no se revirtió ya que Fujimori mantendría la situación autoritaria durante una década tras su autogolpe en 1992. Cabe precisar, que esta coyuntura no se centró exclusivamente en el apartado institucional y es que en tales condiciones la ciudadanía organizada (sociedad civil) también se inhibió dentro de este panorama, sea porque fueron amenazados por la subversión o porque pudieron ser tildados de cómplices del terrorismo por parte del Estado (Díaz-Albertini, 2001, p. 124). Además, lo acontecido no se limitó exclusivamente al sufragio pasivo y activo, sino que derechos básicos como el libre tránsito fueron supeditados a las órdenes de los militares: «se tenía que pedir permiso a las autoridades de facto para poder movilizarse» (CVR, 2003, p. 296).

Nuestra tesis apunta a que tras el regreso democrático materializado en las elecciones de 1980, sobre el terreno no se tradujo en verdaderas libertades políticas en términos de ejercicio o práctica por parte de los ciudadanos de las zonas rurales, 
principalmente por la limitación obligada tanto por el senderismo (cuyas acciones comenzaron casi en paralelo al período democrático) como por las fuerzas de seguridad del Estado, cuya aparición in situ se dio a partir de 1982; coyuntura que se mantuvo durante la década de los años ochenta y continuó durante los años noventa bajo el régimen de Alberto Fujimori, cuando la mayor parte de las libertades políticas seguían bajo tutela militar en estas áreas del país, incluso con la celebración de elecciones (aunque cuestionada su legitimidad). Nuestra hipótesis remarca que, en primer lugar, la limitación en materia de derechos políticos se haya dado bajo un período plenamente democrático (la década de los años ochenta) y, en segundo lugar, pese a la captura y el descenso de la amenaza armada durante la década de los noventa, se mantuviese una limitación en materia de libertades por las autoridades castrenses en las mismas zonas. Esto ha llevado a que la transición democrática iniciada en 1980 no lograse el objetivo del establecimiento de un régimen liberal-democrático y, peor aún, la reimplantación de un régimen aparentemente democrático no demostró un cambio real de régimen (más allá de la celebración de elecciones) entre lo que fue la década autoritaria, previa de los años setenta y el nuevo ciclo democrático. En última instancia, esto se ha traducido en un rechazo o falta de identificación a nivel ciudadano en las zonas rurales dado que los «beneficios» de la democracia no fueron notados durante aproximadamente veinte años por lo que el apoyo al sistema democrático ha quedado mermado y actualmente se ha reflejado en las encuestas de los últimos años a diferencia de lo acontecido en Bolivia y Ecuador, donde las libertades políticas no se suprimieron en las zonas afectadas durante largos años.

\section{Conclusiones}

Tras un análisis de diez años (2006-2016) del soporte democrático en los territorios de la zona andina central (a través de las encuestas de la base de datos de LAPOP), se ha podido obtener que, en Ecuador y Bolivia, las zonas rurales han mostrado un apoyo al sistema democrático mayor que las áreas urbanas, en contra de lo establecido por diferentes líneas teóricas. Con la aplicación de la técnica de sistemas similares del método comparado, se ha sugerido que la diferencia entre, por un lado, Bolivia y Ecuador, y por el otro, Perú, responde al grado con que se desarrolló la lucha interna entre diversos grupos guerrilleros, que durante las últimas décadas del siglo $\mathrm{XX}$, pusieron en jaque a los sucesivos gobiernos, todo ello articulado a través de una comparativa visual para observar dónde se desató el mayor número de desaparecidos y fallecidos (si en la parte rural o la urbana) y mediante el indicador electoral de la abstención. En el contexto peruano, el impacto de organizaciones como Sendero Luminoso o el MRTA, frente al Estado, fue de tal envergadura que en las zonas afectadas, principalmente las rurales, derechos fundamentales quedaron suprimidos durante veinte años como medio para restablecer el orden social dentro de un régimen de libertades, lo que ha 
podido traducirse en una escasez democrática que ha quedado reflejada décadas más tarde, a diferencia de Bolivia y Ecuador donde la subversión no incidió hasta el punto de trastocar el orden civil democrático.

A partir de lo trabajado en este proyecto, cabe cuestionarse ciertos puntos ya establecidos. Por ejemplo ¿una creciente urbanización global ha conllevado verdaderamente a una mayor democratización? ¿Realmente existe hoy una desconexión entre la democracia y las zonas rurales? ¿Existen patrones diferentes en la zona andina con relación a países de otras regiones? Futuras investigaciones pueden indagar en ello, al igual que la refutación de distintas explicaciones que puedan concretar las consecuencias de esta tendencia en torno al apoyo del sistema democrático. La zona de la región andina continua siendo un caso preciso de análisis, sobre todo si puede extenderse posibles investigaciones sobre los dos países de la subregión que en este escrito no se han tratado: Venezuela y, sobre todo, Colombia ya que en este último, el conflicto armado también ha marcado la historia contemporánea del país; si se logra identificar un patrón similar al de la experiencia peruana (es decir mayor apoyo en las zonas urbanas que en las rurales) en contra de lo que pueda extraerse de Venezuela, podría consolidarse la hipótesis que los diferentes conflictos armados se presentan como una condición explicativa en torno al apoyo del sistema liberal democrático dentro del eje urbano-rural al menos en la zona sur de América. 


\section{Bibliografía}

Alcántara, M. (2013). Sistemas políticos de América Latina (4ta ed.). Madrid: Tecnos.

Asociación de Familiares de Detenidos Desaparecidos y Mártires por la Liberación Nacional (2007). Informe sobre las desapariciones forzadas en Bolivia. Recuperado de: http://www.dhnet.org.br/verdade/mundo/bolivia/cv 04 bolivia libro asofan.pdf

Bernales, E. (1985). Ayacucho: hambre y esperanza. Lima: Mosca Azul.

Berrebi, C. y Klor, E. (2006). On Terrorism and Electoral Outcomes. Journal of Conflict Resolution, 50(6), 899-925.

Booth, J. y Seligson, M. (2009). The legitimacy puzzle in Latin America: Political support and democracy in eight nations. Cambridge y Nueva York: Cambridge University Press.

Caïs, J. (1994). Métodos y Estrategias. Metodología del análisis comparativo. Madrid: Centro de Investigaciones Sociológicas.

Chari, R. (2004). The 2004 Spanish Election. Terrorism as a Catalyst for Change?. West European Politics, 27(5), 954-963.

Comisión de la Verdad (2010). Informe de la Comisión de la Verdad Ecuador 2010. Recuperado de: https://www.elcomercio.com/uploads/files/2018/01/08/IE-002.01-2016. pdf

Comisión de la Verdad y Reconciliación (2003). Informe Final. Recuperado de: http://cverdad.org.pe/ifinal/index.php

Dahl, R. (1989). La poliarquía. Participación y oposición. Madrid: Tecnos.

Dalton, R. (1999). Political support in advanced industrial countries. En: Norris, P. (Ed.), Critical citizens: global support for democratic governance. UK: Oxford University Press.

Dargent, E. (2011). Élites precarias: élites y debilidad democrática en el Perú y América Latina. Lima: IEP.

Darlic, V. (1989). Estadísticas Electorales del Ecuador 1978-1989. Quito: SENAC-ILDIS.

Díaz-Albertini, J. (2001). La participación política de las clases medias y las «ongds» en el Perú de los noventa. América Latina Hoy, 28, 115-147.

Easton, David. 1975. A re-assessment of the concept of political support. British Journal of Political Science, 5(4), 435-457.

García, J. (2007) Voting after the Bombing: Can Terrorist Attacks Change the Outcome of Democratic Elections. Barcelona: UPF.

Herrera, A. y Markoff, J (2013). Presentación. Ayer, 83(1), 13-19.

Herrera, A., Markoff, J. y Villa, I. (2013). La democratización del mundo rural en España en los albores del siglo XX. Una historia poco conocida. Ayer, 83(1), 21-42. 
Huntington, S. (1991). El político en las sociedades en cambio (2da Ed.). Barcelona: Paidos.

Jiménez, R. y Franchi, T. (2016). ¿Terrorismo en América del Sur? El caso de Alfaro Vive Carajo. Revista Conjuntura Austral, 35, 52-66.

Langer, G. y Cohen, J. (2005) Voters and Values in the 2004 Election. Public Opinion Quarterly, 69 (5), 744-759.

Laski, H. (1935). Democracy. En Seligman, E. y Johnson, A. (Eds.), Encyclopaedia of the social sciences, Vol. V., 76-85. Recuperado de: https://archive.org/details/in.ernet. dli.2015.460514

Lavrard, C. (2009). Violencia terrorista, pobreza y prácticas democráticas en el Perú (1978-2006). En Baby, S., Compagnon, O. y González Calleja, E. (Eds.), Violencias y transiciones políticas a finales del siglo XX (pp. 225-240). Madrid: Casa de Velázquez.

Lipset, S. M. (1959). Some Social Requisites of Democracy: Economic Development and Political Legitimacy, American Political Science Review, 53(1), 69-105. [Versión en castellano: Algunos requisitos sociales de la democracia: Desarrollo económico y legitimidad política. En Batlle, A. (ed.), Diez Textos Básicos de Ciencia Política (pp. 113150). Madrid: Ariel.]

Norris, P. (1999). Introduction: The growth of critical citizens. En Norris, P. (Eds), Global support for democratic goverment. Oxford: Oxford University Press.

Mansilla, H. (2016). La violencia política en el Perú (1980-1992): una interpretación basada en la cultura política del autoritarismo. Estudios Bolivianos, 25, 121-153.

Martí i Puig, S. (2001). ¿Y después de las transiciones qué? Un balance y análisis de las teorías del cambio político. Revista de Estudios Políticos Nueva época, 113, 101-124.

Mayorga, R. A. (2005). La crisis del sistema de partidos políticos en Bolivia: causas y consecuencias. Canadian Journal of Latin American \& Caribbean Studies, 59, 55-92.

Melgar, W. (2008). Redimensionando la población rural. La Revista Agraria, 101, 11-12.

Melgar, W. (2011). El voto rural en primera vuelta y lo que podría suceder en segunda. La Revista Agraria, 128, 8-9.

Monsivais-Carrilo, A. (2020). La indiferencia hacia de la democracia en América Latina. Revista Íconos, 66, 151-171.

Pachano, S. (2008). Calidad de la democracia y colapso del sistema de partidos Ecuador. Ponencia presentada el seminario partidos políticos calidad de la democracia. México: Instituto Federal Electoral.

Pachano, S. (2012). Calidad de la democracia en los países andinos. En Murakami, Y. (Ed), Dinámica político-económica de los países andinos (pp. 39-80). Lima: IEP/CIAS

Pareja Pflucker, P. y Gatti Murriel, A. (1990). Evaluación de las elecciones municipales de 1989: impacto político de la violencia terrorista. Lima: Instituto Nacional de Planificación. 
Tanaka, M. (1998). Los espejismos de la democracia. El colapso del sistema de partidos en el Perú, 1985-1990. Lima: IEP.

Trujillo, J. M. y Ortega, C. (2015). Un estudio ecológico del voto socialista en el medio rural-urbano andaluz, 1999-2012. Revista Española de Investigaciones Sociológicas, 152, 143-166.

Vergara, A. (2012). Conflicto regional, estado central y sociedad periférica en Bolivia y Perú. Un análisis histórico comparado (Tesis Doctoral). Université de Montréal.

Wirth, L. (1938). Urbanism as a Way of Life. The American Journal of Sociology, 44(1),124 .

Zavaleta, M. (2014). Coalición de independientes: las reglas no escritas de la política electoral. Lima: Instituto de Estudios Peruanos.

\section{Bases de datos}

Barómetro de las américas (LAPOP) https://www.vanderbilt.edu/lapop-espanol/acercaamericasbarometer.php

Banco Mundial. https://datos.bancomundial.org

Global Terrorism Database (GTB). https://www.start.umd.edu/gtd/

Global Data Lab. https://globaldatalab.org

INE - Instituto Nacional de Estadística. https://www.ine.gob.bo/

INEC - Instituto Nacional de Estadística y Censos. https://www.ecuadorencifras.gob.ec/ institucional/home/

INEI - Instituto Nacional de Estadística e Informática. https://www.inei.gob.pe/ 